\title{
Indices of bluefin tuna (Thunnus thynnus thynnus) abundance derived from sale records of French purse seine catches in the Mediterranean sea
}

\author{
Marc Labelle ${ }^{(1)}$, Thierry Hoch ${ }^{(1)}$, Bernard Liorzou ${ }^{(2)}$ and Jean-Louis Bigot ${ }^{(2)}$ \\ Institut Irancais de Recherche pour l'Exploitation de la Mer (IFREMER) \\ (1) Laboratoire de mathématique appliquée à l'èvaluation des ressources halieuliques et aquacoles, \\ rue de l'Ile d'Yeu, B.P. 21105,44311 Nantes Cedex 3, France. \\ E-mail: mlabelle@ifremer.fr \\ (2) Laboratoire d'écologie halieutique, rue Jean Vilar, 34200 Sète Cedex 2, France. \\ E-mail: bliorzou@ifremer.fr
}

Received February 28, 1997; accepted September 12, 1997.

Abstract

Résumé

Labelle M., T. Hoch, B. Liorzou, J.-L. Bigot. Aquat. Living Resour., 1997, 10, $329-342$.

Sampling operations are not routinely conducted in France to monitor the landings of bluefin tuna caught by purse seiners in the Mediterranean. The length, weight and age frequencies of bluefin caught by this fleet are predicted based on salc records, length-at-age and weight-length relations, trends in fishing and natural mortality ratcs, and other ancillary data. The resulting length frequencies are more accurate than those predicted by Liorzou and Bigot (1992) using a simpler algorithm, and are spread more evenly across adjacent size classes. Catch-per-unit-effort (CPUE) was expressed as the numbers of age 2 bluefin caught per successful seine fishing trip in the Gulf of Lions fall fishery. CPUE indices were computed by several methods, and compared to that of the spanish baitboat fishery in the Bay of Biscay. The index trends of the french and spanish fleets exhibit a general increase during 1970-95, but the results do not demonstrate which of these is the best indicator of juvenile abundance. Complementary surveys are required to determine the temporal and spatial distributions of surface schools and fishing effort, and identify the most reliable index of abundance.

Keywords: Bluefin tuna, purse seine, catch-per-unit-effort, abundance indices, growth rates, stock-assessment, Mediterranean sea.

Indices d'abondance du thon rouge (Thunnus thynnus thynnus) dérivés des fiches de vente des captures de senneurs français en Méditerranée.

Des opérations d'échantillonnage ne sont pas effectuées régulièrement en France pour suivre les débarquements de thon rouge capturé par les senneurs en Méditerranée. Les tailles, poids, et fréquences d'âge des thons rouges capturés par cette flottille sont prédits à partir des fiches de mareyeur, des relations taille-âge, des tendances en mortalité naturelle et par pêche, et des données auxiliaires. Les fréquences par taille prédites sont plus exactes que celles obtenues par Liorzou et Bigot (1992) à partir d'un algorithme plus simple, et sont réparties plus uniformément sur les catégories de taille adjacentes. Les prises par unité d'effort (PUE) sont exprimées par le nombre de thons rouges d'âge 2 capturés par marée positive dans le golfe du Lion en automne. Les indices de PUE, calculés de plusieurs façons, sont comparés à celui de la flottille de canneurs espagnols pêchant dans le golfe de Gascogne. Les indices des flottilles espagnoles et françaises révèlent une augmentation générale durant les années 1970-95, mais les résultats ne démontrent pas quel est le meilleur indicateur d'abondance de juvéniles. Des programmes de suivi complémentaires sont requis pour déterminer la distribution spatio-temporelle des bancs de surface et de l'effort de pêche, et identifier l'indice d'abondance le plus fiable.

Mots-clés : Thon rouge, senne tournante, prises-par-unité-d'effort, indices d'abondance, taux de croissance, évaluation des stocks, mer Méditerranée. 


\section{INTRODUCTION}

\section{Fishery characteristics}

Mather et al. (1995) described the historical developments of north Atlantic bluefin tuna (Thunnus thynnus thynnus) fisheries. French fishemen have been catching bluefin tuna in the western Mediterranean for several centuries, but Mather et al. (1995) noted that bluefin catches in that region were "evidently unimportant prior to the development of the French scine fishery in 1960". Farrugio (1977, 1981) described developments in this fishery, and details on other Mediterranean bluefin fisheries were summarized recently (Anonymous, $1995 a$ ).

During the 1970s, French fishermen caught bluefin tuna primarily with small scine vessels while targeting anchovies and sardines. The construction of new vessels specifically designed to harvest bluefin in the Mediterranean started in the late 1970s. The discovery of spawning aggregations of large bluefin near the Baleares Islands during the 1980 s lead to an increase in the number of larger vessels $(>30 \mathrm{~m})$, the formation of partnerships, the use of collaborative fishing strategies, and the adoption of new technologies. In 1996, 45 French purse seine licenses were available to harvest bluefin in the Mediterranean, but only 34 registered vessels participated in the fishery. Most of these were in the 24-36 m size range (Anonymous, 1996).

French purse seine vessels typically target small $(<30 \mathrm{~kg})$ bluefin in the Gulf of Lions and the Catalane Sea from March to May, and throughout coastal waters from Spain to Italy during June-July and SeptemberDecember. They target spawning aggregations of large blucfin $(>30 \mathrm{~kg}$ ) near the Baleares Islands from midMay to mid-July (Fig. 1). The purse seines used tend to be of similar sizes, measuring $1500-1800 \mathrm{~m}$ in length, by $200 \mathrm{~m}$ in depth (stretched). Fishing trips typically last 1-3 d owing to the lack of large storage facilities. The only exception is when catches can be transferred to shipping vessels, as when large vessels concentrate on the spawning grounds near the Baleares Islands.

Tuna schools are traditionally located by means of visual clues and sonar. Spotter planes have been used since 1982, mainly for fishing near the Baleares Islands. Net setting and retrieving operations typically last about two hours. Some fishermen try to limit catches to 80 metric tons (t) per set to facilitate hauling and handling operations, but sets of up to $300 \mathrm{t}$ are made near the Baleares Islands. Once the seine is deployed, other vessels may occasionally provide assistance, and load a portion of the catch in their holds. It has been reported that about half the sets result in no catches. The spatial and temporal distribution of empty sets is unknown, but no evidence was obtained to indicate that their frequency has changed systematically over the years. Empty sets can result from net damage, difficulties during hauling operations, and the absence of tuna, but the nature of the factors responsible for most empty sets has not been determined from fishermen reports or observer programs.

The agency responsible for managing French fisheries, the Affaires Maritimes, does not routinely collect logbooks from seiners that harvest bluefin in the Mediterannean. Furthermore, there is not coast-wide monitoring program to provide data on seine fishing activity, fishing conditions, and catch composition. However, seafood traders (or "mareyeurs") keep records of bluefin sold to markets in France, Spain and Italy.

Each record indicates a sector where the calch is landed (Fig. 1). For 1970-81, the sectors were unknown (1), Port-Vendres (2), Gulf of Lions (3) and Gulf of Genoa (4). For 1982-93: unknown (1), PortVendres (2), Sète (3), Martigues (4), Marseille (5), Toulon (6), Nice (7), Ajaccio (8), Bastia (9), Spain (10), and Italy (11). Since 1994, the last two are subdivided (Spain: 101, 102, 103, etc.; Jtaly: 111, 112, 113, etc.). Scale records also indicate the trader, the vessel, the sale date, the total weight and number of bluefin in each container. The bluefin are not gutted, separated by sex, or individually weighted. The sale date follows the fishing period because most trips are short $(<3 \mathrm{~d})$ and the catch is sold when landed. The sector is usually close to the fishing grounds because most vessels operate near their home port.

Each year, scientists from the Institut Français de Recherche pour l'Exploitation de la Mer (IFREMER) ask the mareyeur to provide copies on sale records to help monitor activities in this fishery. Not all sale records are supplied, and some are incomplete or contain crrors (invalid dates, unrealistic weights, etc.). Efforts are made to correct apparent errors, but if no correction is justified, the record is considered as incomplete and not used for detailed studies.

A total of 25231 records were provided over 197095, of which $89.6 \%$ are complete (Table 1). The reporting rate (total catch of complete records over total fleet catch) exceeded $90 \%$ in some years, and averaged $51 \%$ over this period. A cursory examination of these data revealed no peculiar pattern in reporting rates and record completeness across time and sector strata. These data are considered to be a fairly representative sample of the French purse seine catches and landings, and are assumed to reflect changes in fishing patterns and catch composition for successful fishing trips when at least one bluefin was caught, landed and sold.

\section{Study objectives}

To assess the status of north Atlantic bluefin, the International Commission for the Conservation of Atlantic Tunas (ICCAT) requires that contracting states provide the length frequencies of bluefin catches, and if possible, indices of abundance by age and fishery. The former serve to generate the catch-atage matrices, while the later help calibrate models used to conduct sequential populations analyses (SPA). 


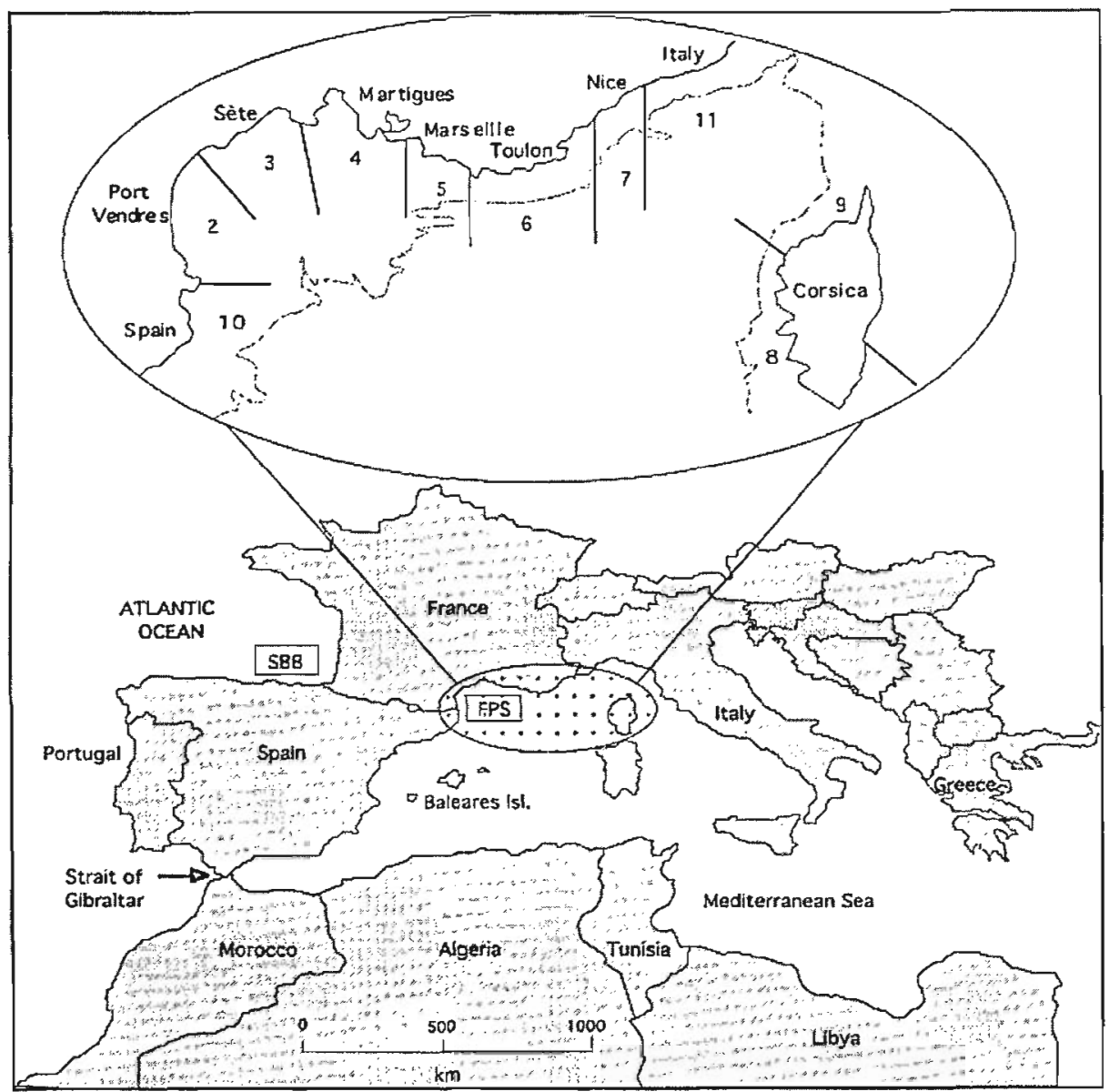

Figure 1. - Location of the principal index sites and fishing sectors used for reporting purposes. The site labels represent the Spanish baithoat fishery (SBB) in the Bay of Biscay, and the French purse scine fishery (FPS) in the Gulf of Lions. Dotted line at edge of zones indicates the $1000 \mathrm{~m}$ depth contour.

The 1970-93 length frequencies used for ICCAT assessments (Anonymous, $1995 \mathrm{~b}$, p. 140) were derived from sale records. For each container, a mean bluefin weight was estimated from the total weight divided by the number of bluefin in it. All bluefin in a given container were assumed to have the same fork length $(\mathrm{L}$, in $\mathrm{cm})$, predicted from the mean bluefin weight $(\mathrm{W}$, in $\mathrm{kg})$ using the relation $\mathrm{L}=36.6 \mathrm{~W}^{0.3323}$ (Anonymous, 1995, p. 24). The frequency distributions supplied to ICCAT were thus the converted mean weights, pooled and expanded by the reciprocal of the reporting rate. This prediction method, first used by Liorzou and Bigot (1992), was considered to be overly simplistic, but was relied upon until 1996 for lack of a better alternative.

The main ojective of the present study was to develop a superior algorithm to predict $(i)$ the length frequencies bluefin in French purse seine catches, and (ii) trends in catch-per-unit-effort (CPUE) of juvenile bluefin, using the sale records, ancillary data on the demographic traits of the bluefin population, and the exploitation characteristics of the French purse seine fleet. In the following sections, the features of this new algorithm are described in detail, its predictive ability is assessed and compared to that of the previous algorithm used by Liorzou and Bigot (1992).

\section{MATERIALS AND METHODS}

\section{Data availability}

The records selected were from September and October, in sectors 2-3 for 1970-81, and 2-4 for 198295 (Fig. 1). When too few records $(<10)$ were available for that period, those from early November or late August were included to increase the sample sizes. For years prior to 1975 , records from sector 1 (unknown) were included to increase sample size. This addition is reasonable since catch patterns in this sector are most 
Table 1. - Summary of fish sale records used in the present seudy. Sample wcight is the total weight of the catch for complete records (in metric tons). Reporting rate is the ratio of the sample to total fleet catch (by weight). The reciprocal of the ratio is labelled C/S.

\begin{tabular}{|c|c|c|c|c|c|c|}
\hline $\begin{array}{c}\text { Survey } \\
\text { year }\end{array}$ & $\begin{array}{l}\text { Total } \\
\text { records }\end{array}$ & $\begin{array}{l}\text { Complete } \\
\text { records }\end{array}$ & $\begin{array}{c}\text { Salmple } \\
\text { (t) }\end{array}$ & $\begin{array}{l}\text { Total catch } \\
\text { (1) }\end{array}$ & $\begin{array}{l}\text { Reporting } \\
\text { ratc }\end{array}$ & $\mathrm{C} / \mathrm{S}$ \\
\hline 1970 & 186 & 169 & 249 & 1100 & 0.23 & 4.42 \\
\hline 1971 & 166 & 140) & 549 & 2200 & 0.25 & 4.01 \\
\hline 1973 & 152 & 116 & 336 & 1400 & 0.24 & 4.17 \\
\hline 1974 & 110) & 72 & 321 & 1800 & 0.18 & 5.61 \\
\hline 1975 & 266 & 254 & 520 & 1600 & 0.33 & 3.08 \\
\hline 1978 & 607 & 594 & 720 & 1506 & 0.46 & 2.18 \\
\hline 1979 & 1356 & 1340 & 1002 & 1527 & 0.06 & 1.52 \\
\hline 1980 & 1202 & 1202 & 993 & 1701 & 0.58 & 1.71 \\
\hline 1981 & 540 & 454 & 1610 & 23010 & 0.70 & 1.43 \\
\hline $19 \times 2$ & 1084 & 1052 & 4487 & 4818 & 0.93 & 1.07 \\
\hline 1983 & 160 & $160)$ & 768 & $3600)$ & 0.21 & 4.69 \\
\hline 1988 & 906 & 629 & 2533 & 5750 & 0.44 & 2.27 \\
\hline 1989 & 965 & 801 & 2866 & 4404 & 0.65 & 1.54 \\
\hline 1990) & 1546 & 1242 & 3382 & 4663 & 0.73 & 1.38 \\
\hline 1991 & 1592 & 1392 & 3684 & 4570 & 0.81 & 1.24 \\
\hline 1992 & 1439 & 1338 & 4491 & 5070 & 0.75 & 1.33 \\
\hline 1993 & 2929 & 2823 & 3130 & 4730 & 0.06 & 1.51 \\
\hline 1994 & 3073 & 2816 & 4534 & 11800 & 0.38 & 2.60 \\
\hline 1995 & 1236 & 888 & 3728 & 8220 & 0.45 & 2.20 \\
\hline Sum & 25231 & 22599 & 52069 & 98531 & 0.53 & 1.89 \\
\hline
\end{tabular}

similar to those of sector 3 . The records for October 1987 were excluded since most were from one vessel that never sold small bluefin.

A cursory examination of these data indicated that the catch was composed mainly of age groups 2 and 3 , with the former being more abundant, in all strata. Therefore, the main CPUE measure used in this study was based on age 2 catches, but CPUE trends based on age 3 catches are also generated separately to conduct further comparisons. As a result of this selection, only $22 \%$ of the 22599 complete sale records served to determine CPUE trends for 1970-95, which after pooling by vessel-trip yielded 1736 CPUE scores with catches of age 2 bluefin (Table 2 ).

\section{Analytical approach}

The procedure used to predict the length, weight, and age frequencies of bluefin in a container rests on two key assumptions. The first is that bluefin segregate into schools of bluefin having similar body sizes, and that this natural grouping is not broken by harvesting and sorting activities conducted before the catch is sold. In support of this hypotheses, Mather et al. (1995) noted that bluefin in the Mediterranean school "very strictly according to size" except during the short reproductive period. Also, fishermen tend to keep catches from different sets in separate containers to minimize disturbances to the blucfin already stored, and reduce the need to son the catch by size before selling it.

The second assumption is that the mean weight of the bluefin in a container is equal to the expected mean weight of a group of bluefin sampled from a population that grows according to the von Bertalanffy model, and is subject to natural and lishing mortality during its existence. Several studies have confirmed that the growth of temperate tuna species conforms fairly well to this model over most of their life span (Fournier et al., 1990; Hampton, 1991; Cort, 1991; Labelle et al., 1993), although bluefin growth in the first 12 months tends to conform more to Gompertz model (Deriso and Bayliff, 1991).

The model relies on a few simple functions linked within a simulation framework, rather than on extensive analytical solutions. This approach, based on Monte Carlo methods, was chosen mainly to allow for stochastic effects, which are accounted for through several randomized sampling operations. As will be shown in later sections, this approach also allows sensitivity analyses to be conducted easily by changing some of the underlying functions.

Information on length-at-age, weight-length relations, and trends in fishing and natural mortality is used in a model to produce a set of expected frequencies in length-at-age, that are converted based on a length-weight relation to predict the plausible age group contributions to each possible $1 \mathrm{~kg}$ category of 


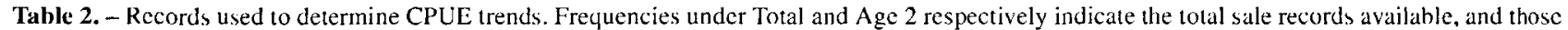

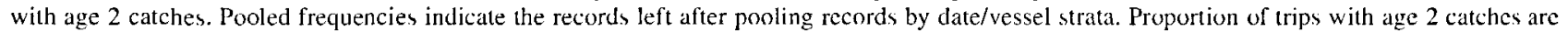
calculates from these pooled frequencies.

\begin{tabular}{|c|c|c|c|c|c|c|c|c|c|c|c|}
\hline Year & \multicolumn{4}{|c|}{ Total } & \multicolumn{4}{|c|}{ Age 2} & $\begin{array}{l}\text { Pooled } \\
\text { total }\end{array}$ & $\begin{array}{c}\text { Pooled } \\
\text { agc } 2\end{array}$ & $\begin{array}{c}\text { Age } 2 \\
(\% \text { total })\end{array}$ \\
\hline 1970 & 11 & 10 & 11 & & 3 & 1 & 3 & 7 & 26 & 7 & 0.27 \\
\hline 1972 & 6 & 2 & 0 & & 3 & 0 & 0 & & 8 & 3 & 0.38 \\
\hline 1973 & 3 & 6 & 9 & & 0 & 0 & 6 & & 15 & 4 & 0.27 \\
\hline 1974 & 3 & 26 & 0 & & 0 & 6 & 0 & & 28 & 6 & 0.21 \\
\hline 1977 & & 0 & 106 & & & 0 & 45 & & 95 & $4 I$ & 0.43 \\
\hline 1978 & & 0 & 5 & 37 & & 0 & 5 & 26 & 37 & 28 & 0.76 \\
\hline 1979 & & 8 & 376 & & & 0 & 203 & & 40 & 25 & 0.63 \\
\hline 1980 & & 12 & 8 & & & 12 & 4 & & 17 & 13 & 0.76 \\
\hline 1981 & & 84 & 36 & & & 72 & 35 & & 97 & 94 & 0.97 \\
\hline 1982 & & 206 & 183 & & & 181 & 167 & & 246 & 234 & 0.95 \\
\hline 1988 & & 182 & 101 & & & 129 & 68 & & 136 & 112 & 0.82 \\
\hline 1989 & & 197 & 52 & & & 95 & 46 & & 106 & 90 & 0.85 \\
\hline 1990 & & 193 & 41 & & & 158 & 35 & & 115 & 103 & 0.90 \\
\hline 1991 & & 235 & 183 & & & 201 & 151 & & 253 & 232 & 0.92 \\
\hline 1992 & & 251 & 1.36 & & & 210 & 104 & & 157 & 150 & 0.96 \\
\hline 1993 & & 66 & 85 & & & 59 & 79 & & 110 & 105 & 0.95 \\
\hline 1994 & & 120 & 507 & & & 59 & 262 & & 103 & 86 & 0.83 \\
\hline 1995 & & 115 & 111 & & & 91 & 37 & & 174 & 115 & 0.66 \\
\hline Total & 68 & 2724 & 2206 & 37 & 30 & 1760 & 1416 & 26 & 2154 & 1736 & \\
\hline
\end{tabular}

mean bluefin weight per container. The number of random weights drawn from each age distribution is a function of the numbers in a container, the predicted contribution of each age group, and the expected survival-at-age. The predicted weights of all bluefin in a container are summed, and compared to the container weight. If the two figures do not match, re-sampling is conducted to ensure that the final predictions are plausible. The predicted fork lengths, pooled across all containers, and expanded by the reciprocal of the reporting rates, yields the predicted length frequencies associated with total catches.

In the absence of an established procedure for determining CPUE trends, indices were computed by several methods. The basic CPUE measure used in this analysis is the catch of bluefin of an age group per successful trip. In the absence of data on unsuccessful trips, and details on the vessel characteristics, standardized indices cannot be computed with Generalized Linear Models (GLM) as proposed by Stefánsson (1996). To cope with such constraints, and minimize the need for standardization, CPUE trends are based only on sale records from a traditional fishery that covers a well defined spatio-temporal stratum of suitable bluefin habitat. Bayliff (1995) used a similar approach to calculate abundance indices for eastern Pacific bluefin from CPUE scores.
The fall fishery in the Gulf of Lions was selected for the present purposes. This is a relatively productive area where bluefin aggregate to feed on sardines and anchovies, and are available for year-around fishing. This area is close to the coast, and is accessible to traditional purse seine vessels that are not modified to harvest the summer spawning aggregations of large bluefin near the Baleares Islands. The distinction between these two types of fisheries is clearly reflected in the sale records data (Fig. 2).

\section{Symbols and definitions}

The following symbols and definitions will be used to describe the simulation procedure, and the structure of the underlying models.

\section{von Bertalanffy model parameters}

$K \quad$ Growth rate per year

$a_{0} \quad$ Theoretical fork length at age zero

$L_{a} \quad$ Fork length $(\mathrm{cm})$ of a bluefin at age $a$ (in years)

$L_{\infty} \quad$ Asymptotic fork length

$G \quad$ Cyclic growth amplitude

$a_{s} \quad$ Cyclic growth start time 


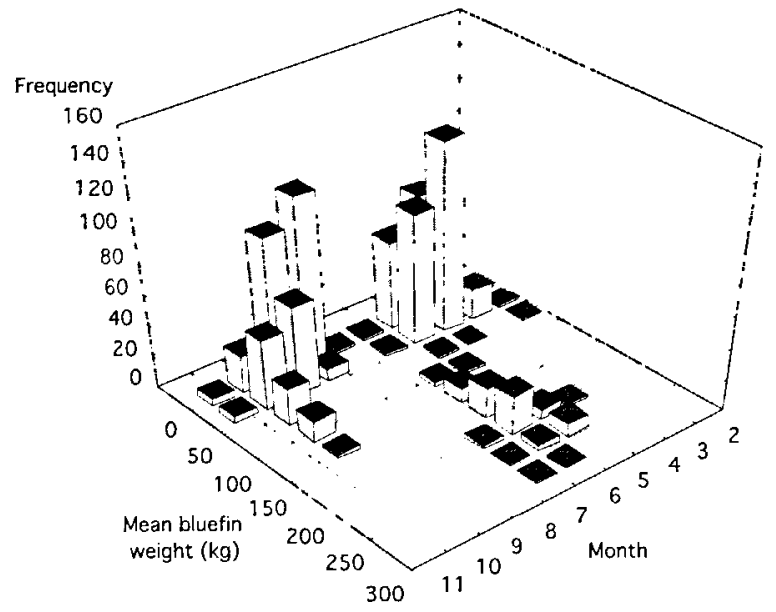

Figure 2. - Distribution of mean bluefin weight per container by month for 1995. Landings of large bluelin occur during the summer when fishermen target spawning aggregations near the Baleares Islands.

Indices designaling integer values of variable subscripts $t$

$a$

$m$

$y$

$d$

$D$

$v$

$b$

$s$
Time, in months; range $0-600 ; t=0$ at birth on July 1

Age group, in years; range 0-50; enter group 1 at $\mathrm{t}=6$

Month of the year; range 1-12

Year

Fishing trip

Number of trips for a vessel during a period

Vessel

Container

Weight category (in $\mathrm{kg}$ ) of container; range $1-700$

Simulation model variables

W Weight of a bluefin ( $\mathrm{kg})$

$L \quad$ Fork length (cm)

$F_{a} \quad$ Instantaneous rate of fishing mortality on an age group

$M \quad$ Instantaneous rate of natural mortality (all age groups)

$R_{t} \quad$ Relative survival rate during time $t$

$I_{t} \quad$ Relative abundance at the beginning of time $t$

$\mathbf{V}_{s, t} \quad$ Storage matrix of dimensions $700 \times 600$ for $1 \mathrm{~kg}$ by 1 month intervals

$v_{a, s, t} \quad$ Matrix cell count for a given age category

$p_{a, b, m} \quad$ Predicted proportion of fish age $a$, in a container of mean weight $s$, in month $m$

$\hat{n}_{a, \ldots} \quad$ Predicted number of bluefin of age $a$, in...
$N_{b, \ldots} \quad$ Reported number of bluefin in container $b$, in...

$\hat{u}_{a, v_{1} \ldots} \quad$ Predicted daily CPUE for age $a$, vessel $v, \ldots$

$\hat{U}_{y, u} \quad$ Predicted overall CPUE of the fleet by year and age

\section{Model structure and simulation procedure}

From an analysis of the circuli patterns in spine sections, Cort (1991) estimated the von Bertalanffy growth parameters to be $K=0.093$ year $^{-1}, L_{\propto}=318.85$ $\mathrm{cm}$, and $\mathrm{a}_{0}=-0.97$ year. Mather and Schuck (1960), Farrugio (1981) and Cort (1991) provided evidence of seasonal fluctuations in growth rates for this species, with faster growth occurring during the July-October period. Therefore, the modified form of the von Bertalanfly model proposed by Pauly and Gaschütz (1979) was used to predict the length of east Atlantic bluefin after $a$ years of growth;

$$
L_{a}=I_{\infty}\left\{1-e^{-k !\left(a-a_{0}\right)+\frac{G}{2 \pi} \operatorname{in}\left(2 \pi\left(a-a_{1}\right)\right)}-\right\}
$$

The von Bertalanffy parameter estimates used were those reported by Cort (1991). The growth cycle coefficients $G$ and $a_{s}$ were estimated from these data by multiple regression as described by Pauly and Gaschütz (1979). The estimates were 0.691 and 0.127 respectively.

The above equation describes trends in mean lengthat-age, but not its variation. For several temperate tuna species, the standard deviation in length-at-age is thought to be a linear function of the mean (Fournier et al., 1990; Labelle et al., 1993). It is assumed that growth of east Atlantic bluefin conforms to this pattern, and that variation in size-at-age about the mean is normally distributed. Length-at-age data for ages 9-15 reported by Cort (1991 p. 218) were used to conduct a linear regression of the standard deviation against the mean. Estimates of the intercept and slope were 4.14 and 0.037 respectively, and the distribution of residuals showed no aberrant pattern. The predicted mean length-at-age and the estimated standard deviation in length-at-age were used to describe growth during the first 600 months of life (Fig. 3).

The plausible contribution of each age group to a container population is determined by numerical simulations. For each of the 600 months of life, random deviates of fork length are generated from a normal distribution with parameters corresponding to the predicted mean and standard deviation in length-at-age. Each length deviate is converted to a weight using the relation established for bluefin (Anonymous, $1995 b$ p. 24):

$$
W=0.0000196 L^{3.0092}
$$



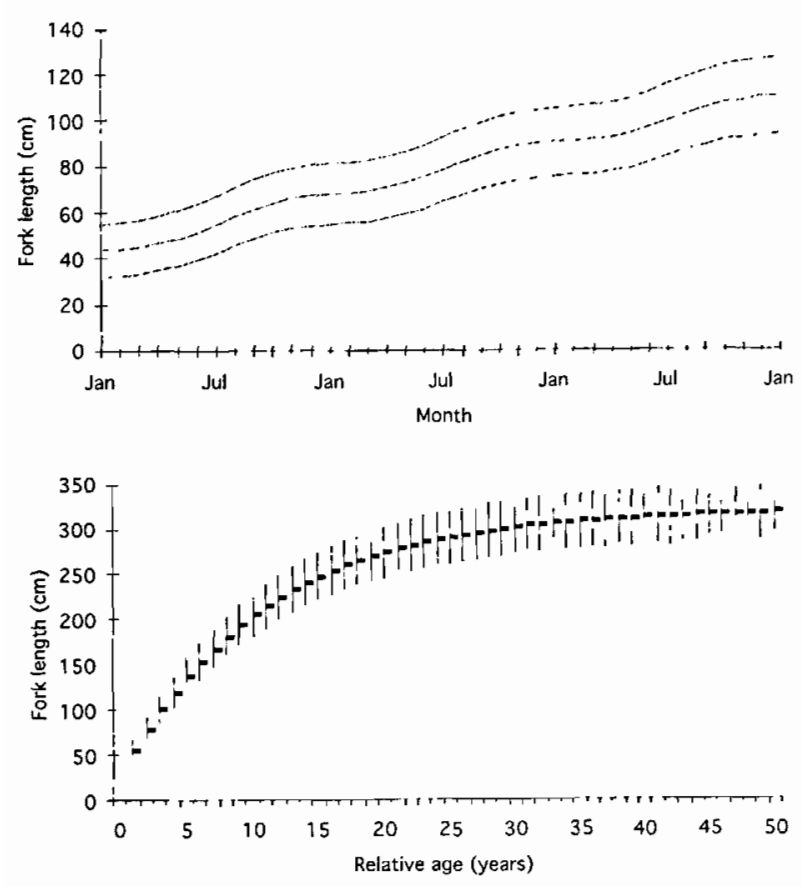

Figure 3. - Growth pattern of cast Atlantic blucfin, showing seasonal variation in growth during ages 1 to 4 (top), and overall trends in length-at-age (bottom). Middle line indicates mean fork length, and middle bars indicate mean length on July 1 . Lower and upper bounds correspond to mean $\pm 2 \mathrm{SD}$. According to the ICCAT convention, age is updated on January first, so bluefin born around June-July enter the age 1 category after $\leq 6$ months of growth.

Each time a random weight deviate is produced, the corresponding cell count of matrix $\mathbf{V}$ is updated. To account for the likely reduction of older bluefin due to accumulated natural and fishing mortalities, the number of random deviates generated for each month is progressively reduced from 10000 to an index of relative abundance computed as follows:

$$
\begin{aligned}
& R_{t}=e^{-\left(\frac{F_{a}+M}{12}\right)} \\
& I_{t}=I_{t-1} R_{t-1}
\end{aligned}
$$

The assumed rates of natural and fishing mortality were based on the results of a recent ICCAT assessments (Anonymous, 1995b). Natural mortality is set to 0.14 per year for all ages. Annual rates of fishing mortalities on ages $1,2-4,5-8$ and $9+$ are set to $0.05,0.40$, 0.07 and 0.11 respectively, and assumed to be spread uniformly throughout the year. This scenario obviously oversimplifies the mortality pattern acting on each cohort, but given the uncertainty associated with mor- tality estimates, a more sophisticated accounting procedure was not justified. The population is thus considered to be at equilibrium, which is necessary in the present context for reasons given in later sections.

Once all the deviates are generated, the matrix columns hold the relative weight-at-age frequencies for every possible combination of age group and monthly time period. The age group contributions to a container population in a mean weight by month category are then predicted from the ratio of the matrix cell counts for a mean weight category:

$$
\begin{gathered}
\hat{p}_{a, s, m}=\frac{\sum_{t} v_{a, s, t}}{\sum_{a} \sum_{t} v_{a, s, t}} \\
\left\{\begin{array}{c}
t \leq 5: a=0: m=t+7 \\
t \geq 6:\left\{\begin{array}{c}
a=1+(|6-t| / 12) \\
m=t-12(a-1)-5
\end{array}\right. \\
\hat{n}_{a, b, v, d, m, y}=N_{b, s, v, d, m, y} \hat{p}_{a, s, m}
\end{array}\right.
\end{gathered}
$$

The total weight of the bluefin in a container is then predicted by randomly sampling $n_{a, b, \ldots}$ times (from Eq. 6) with replacement, from the weight-at-age distributions generated initially for each age by month combination. Re-sampling is conducted to allow bluefin in an age group to vary in weight. This is a necessary step because Eq. 6 only accounts for bluefin in the same weight category, and only serves as a reference point to determine plausible contributions in numbers.

The predicted weights of all bluefin in a container are summed, and compared to the weight reported on a sale record. If the absolute difference between these figures exceeds $10 \%$ of the reported weight, a new set of deviates is generated. Once the two figures match, the final predicted number of bluefin by age group in a container is obtained. By re-converting the $n_{a, b, \ldots}$. weights to fork lengths, the length frequencies of a container population is also predicted. The frequencies representing the total annual fleet catches is obtained by pooling the frequencies by length category across all containers and vessels by month, and multiplying these by the reciprocal of the reporting rate.

In the absence of data on the duration of fishing activities, all trips are assumed to last one day. Basic 
CPUE scores by year, age, vessel, and trip were computed from :

$$
\hat{u}_{a, v, d, m, y}=\sum_{b=1}^{B} \hat{n}_{a, b, v, d, m, y}
$$

Annual CPUE indices are computed with parametric and non-parametric estimators. Nominal CPUE (Index 1) and sample mean CPUE (Index 2) are first computed from :

$$
\begin{aligned}
& \begin{array}{llll}
m=11 & V & D & B
\end{array} \\
& \sum \sum \sum \sum \hat{n}_{a, b, r, d, m, y} \\
& \hat{U}_{a, y}^{\prime}=\frac{m=8 v=1 \quad d=1 h=1}{m=11 \quad V} \\
& \sum_{m-8,-1} \sum_{v, m_{,},} \\
& m=11 \quad V \quad D \\
& \sum \sum \sum \hat{u}_{a, k, d, m, y} \\
& \hat{U}_{a, y}^{\prime \prime}=\frac{m=8 v=1 d=1}{m=11 \mathrm{~V}} \\
& \sum_{m=8} \sum_{\mathfrak{r}=1} D_{\mathfrak{v}, m, y}
\end{aligned}
$$

The Delta-lognormal model described by Pennington (1983) was also used to compute mean annual CPUE (Index 3). When the distributions of values contain zeros, and the non-zero values are lognormally distributed (as in some of the present cases), this estimator can be more efficient than the sample mean (Smith, 1988; Pennington, 1990). Since some of the CPUE distributions did not fall in this category, the univariate model of Richards and Schnute (1992) is also used to compute CPUE (Index 4). This model normalizes the distribution of CPUE scores using maximum likelihood methods to estimate the normalizing parameters. The model yields estimates of CPUE central tendency and the associated likelihood-based confidence regions.

Finally, Index 5 is set to the proportion trips with no catches of age 2 bluefin per season (or 1.0 minus rightmost \% in Table 2). Bannerot and Austin (1983) noted that this proportion explained more variation in abundance than the other CPUE descriptors they tested. In the present context, sale records are only produced when tuna are caught and sold, so this proportion is conditional on some tuna being present on the grounds, and Index 5 may underestimate the actual absence of age 2 bluefin. However, no evidence was obtained to indicate that the frequency of empty sets or the nature of the factors responsible for them has changed over the years, so there is no reason to assume that the trends based on Index 5 have become more or less biased with time.

As a result, five CPUE trends are generated from the French purse seine data with the present algorithm. All computations are made with a FORTRAN 77 program, using IMSL (1989) random number generator, function evaluation and minimization routines, and the vector sorting algorithms of Press et al. (1992). In the following discussion, the end points of the $95 \%$ confidence regions or intervals are referred to as upper and lower bounds. Bounds for Index 2 are \pm twice the sample standard error (Zar, 1984, p. 31), while those of Index 5 as computed as binomial proportions (Zar, 1984 p. 378).

\section{Evaluation procedure}

The accuracy of the predicted length frequencics is assessed by comparing these to the reported figures associated with two landings for which detailed information was available on the catch composition. In both of these cases, the bluefin unloaded were sorted by size and then placed in bins either individually or in small groups (usually $\leq 4$ ). This operation yielded a total of 111 and 150 individual measurements on landings of 1.369 and 488 bluclin respectively.

Since the actual abundance of juvenile bluefin in this region is unknown, inferences on the accuracy of each CPUE index must be based on their theoretical merits, and correlations with independent estimates. Recent ICCAT estimates of stock size were partly based on the present indices, so these could not be used for evaluation purposes (lack of independence). Comparisons were thus made with the nominal CPUE index for the Spanish baitboat fishery in the Bay of Biscay. Cort (1994) reported the trend for this fishery (total catch over total effort), that takes place mainly between June and September. Previous tagging programs revealed that juvenile bluefin travel from this area to the Gulf of Lions (Cort and Liorzou, 1991). It was reasoned that a high correlation between some indices from each fishery would support the hypothesis that these indices can be used to detect changes in juvenile abundance.

\section{RESULTS}

\section{Length frequencies}

The length frequencies predicted with the present algorithm closely matched the observed frequencies associated with two Jandings for which detailed information was available on catch composition (Fig. 4). Predicted frequencies were not consistently higher or lower than observed frequencies, and the range of predicted sizes was almost identical to that of the observations. For vessel 24, the 1369 bluefin landed had an mean weight of $14.0 \mathrm{~kg}$. These were predicted to be mainly of age $2(85 \%)$, with some in ages 1 and $3(7 \%$, $8 \%)$. For vessel 66 , the 488 bluefin landed hand an mean weight of $19.1 \mathrm{~kg}$, and were ages 2 and 3 only (50\% in each). 

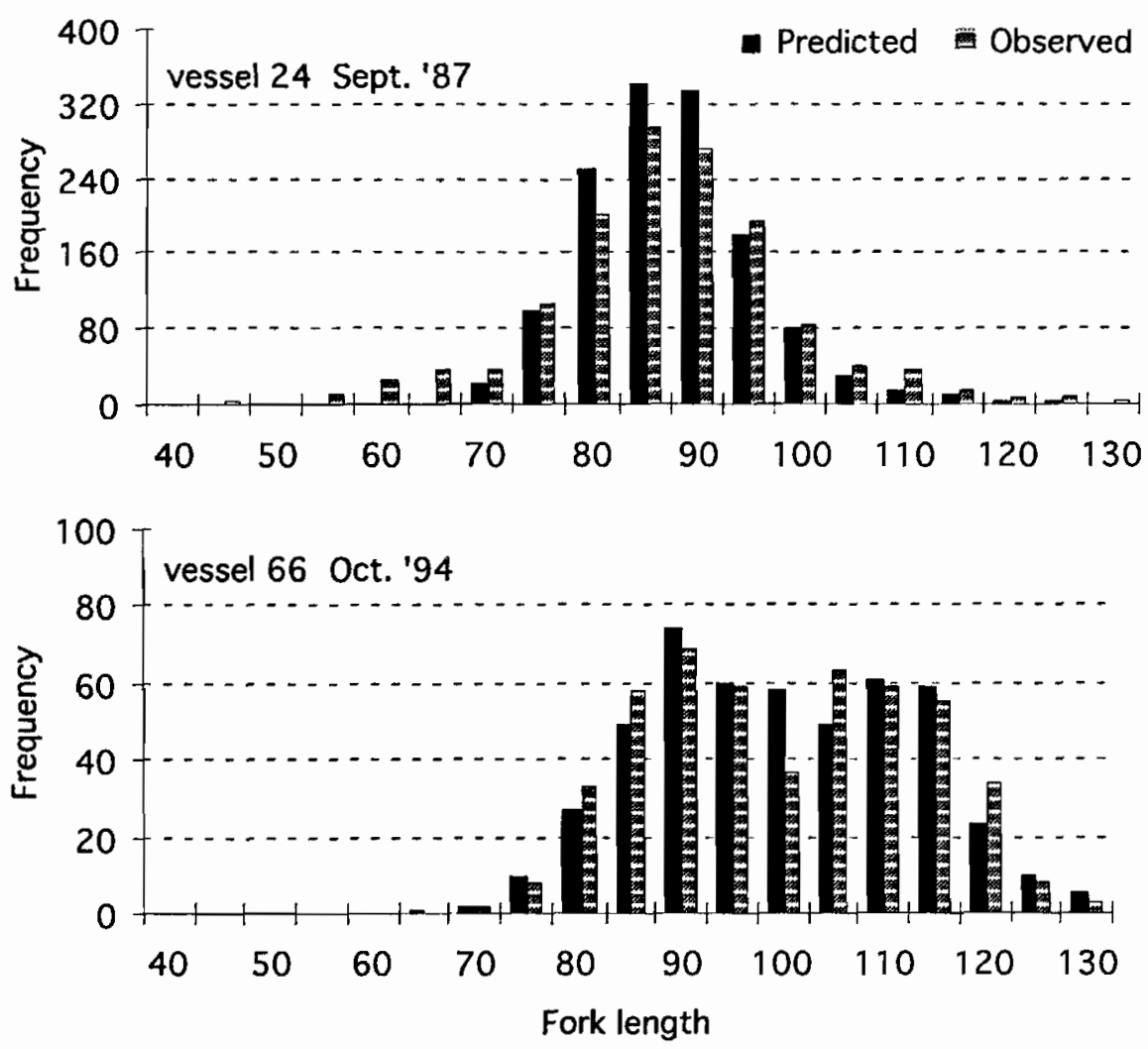

Figure 4. - Predicted and observed length frequencies of bluefin landed on two occasions by purse seine vessels after a single trip. Predicted figures obtained with the present algorithm (fork length in $\mathrm{cm}$ ).

When these two sale records are processed with the previous algorithm used by Liorzou and Bigot (1992), all 1369 bluefin landed by vessel 24 are predicted to be $88.1 \mathrm{~cm}$, and all 488 bluefin landed by vessel 66 are predicted to be $97.8 \mathrm{~cm}$. The previous algorithm does not allow for variation in size among bluefin in a container, and allocates too many frequencies to the size class that corresponds to the mean weight of the container population. These results clearly demonstrate that the predictive capacity of the present algorithm is superior to the previous one, at least when used to predict the catch composition of single landings.

Note that some of the errors of the previous algorithm can cancel out each other when the frequencies are pooled across all trips, vessels, sectors, and periods. Consequently, the length frequency distribution for total fleet catches predicted by the previous algorithm is similar to the present one, which tends to spread frequencies more evenly across adjacent size classes (Fig. 5). The present algorithm also predicts a relatively greater abundance of small bluefin, because the contributions of older age groups are reduced by accounting for the cumulative mortalities. These discrepancies are large enough to induce significant dif-
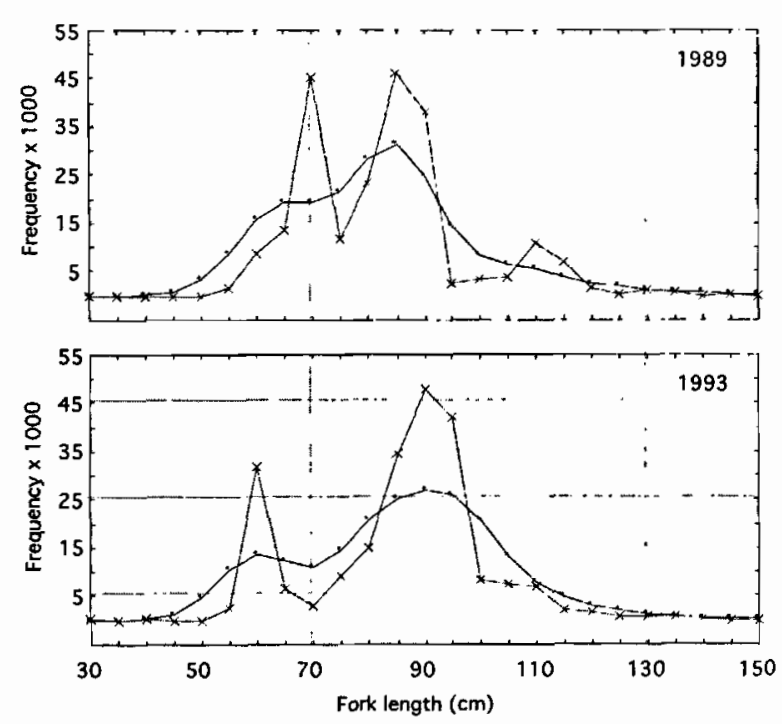

Figure 5. - Length frequencies of bluefin caught by French purse seine vessels during two seasons, as predicted with the present algorithm (dots), and the older algorithm (crosses) used by Liorzou and Bigot (1992). 
ferences over the $40-140 \mathrm{~cm}$ length interval for most years (Chi-square test, $p<0.001$ ).

\section{CPUE trends}

A cursory examination of the distribution of CPUE scores revealed that scores of zero are common in all years (some catch but no age 2 ). The distributions of non-zero scores was positively skewed for most years, and exhibited considerable year-10-year variation in shape. Statistical comparisons of the distributions were hampered by small samples in some cases, and the lack of a standard number of CPUE categories to use for testing purposes. For cases with small samples, the distributions were atypical, but for most others, Kolmogorov-Smirnov tests failed to reject the hypothesis (at $\alpha=0.05$ ) that the distributions conformed either to the lognormal or the gamma.

Spearman rank correlations scores were computed for pair-wise comparisons of indices based on catches of age 2 bluefin. Correlations were also computed using indices 1-5 for catches of age 3 blucfin, and the Spanish baitboat index of age 2 bluefin of the previous year (Table 3 ). The results show that indices 1 and 2 are identical. Since the nominal index is equivalent to the sample mean of CPUE scores, only indices $2-5$ are used for further comparisons (Fig. 6).

Table 3. - Sperman rank correlation cocfficicnts between indices 1-5 for ages 2 and 3 (top and bottom, respectively). Figures in lower box obtained by comparing indices $1-5$ for age 3 with the spanish index for age 2 in the previous year. See text for index descriptions.

\begin{tabular}{|c|c|c|c|c|c|c|}
\hline $\begin{array}{l}\text { Index label } \\
\text { and type }\end{array}$ & 1 & 2 & 3 & 4 & 5 & Spanish \\
\hline 1 Nominal & 1.00 & 1.00 & 0.91 & 0.70 & -0.57 & 0.40 \\
\hline $\begin{array}{l}2 \text { Arithmetic } \\
\text { mean }\end{array}$ & - & 1.00 & 0.91 & 0.70 & -0.57 & 0.40 \\
\hline $\begin{array}{l}3 \text { Delta- } \\
\text { lognormal }\end{array}$ & - & - & 1.00 & 0.80 & -0.70 & 0.34 \\
\hline $\begin{array}{l}4 \text { Richard } \\
\text { and Schnute }\end{array}$ & - & - & - & 1.00 & -0.95 & 0.38 \\
\hline $5 \%$ zero age 2 & - & - & - & - & 1.00 & -0.35 \\
\hline Spanish baitboat & $\cdot$ & - & - & - & - & 1.00 \\
\hline 1 Nominal & 1.00 & 1.00 & 0.96 & 0.66 & -0.42 & 0.60 \\
\hline $\begin{array}{l}2 \text { Arithmetic } \\
\text { mean }\end{array}$ & - & 1.00 & 0.96 & 0.66 & -0.42 & 0.60 \\
\hline $\begin{array}{l}3 \text { Delta- } \\
\text { lognormal }\end{array}$ & - & - & 1.00 & 0.62 & -0.38 & 0.56 \\
\hline $\begin{array}{l}4 \text { Richard } \\
\text { and Schnute }\end{array}$ & - & - & - & 1.00 & -0.91 & 0.36 \\
\hline $5 \%$ zero age 3 & - & - & - & - & 1.00 & -0.25 \\
\hline Spanish baitboat & - & - & - & - & - & 1.00 \\
\hline
\end{tabular}

The Delta-Lognormal and arithmetic mean CPUE trends (Indices 2-3) are very similar, so the gains in precision obtained by using the former estimator are minor in the present context. By contrast, trends based on Index 4 differ substantially from the previous two, and exhibit the strongest negative correlation with
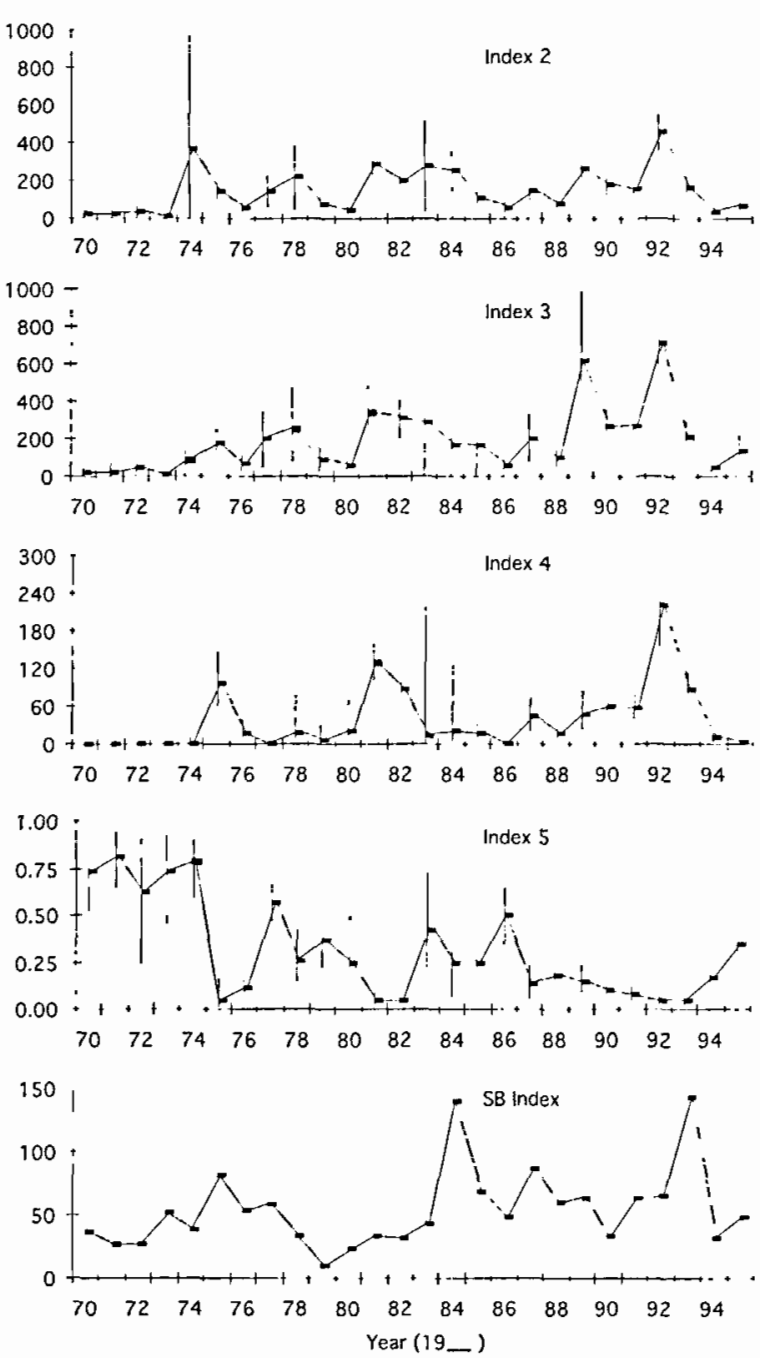

Figure 6. - Trends in catch-per-effort (CPUE) for age 2 bluefin. Midpoints and vertical bars correspond respectively to the index scores and their lower and upper bounds. The indices for the French purse seine are the arithmetic mean (Index 2), Delta-Lognormal (Index 3), Richards and Schnute (Index 4), and to zero age 2 catches (Index 5), lower trends corresponds to the Spanish baitboat (SB Index). See text for descriptions.

Index 5 (Table 3). Theoretically, one would expect such a negative relation since the number of trips with no catches of an age group should be high when densities are low.

None of the purse seine indices are highly correlated with that of the Spanish baitboat fishery, but Index 2 based on catches of ages 2 or 3 exhibited the greatest similarity. A linear regression of Index 2 scores for age 3, against the Spanish baitboat index scores for age 2 (for previous year) was statistically significant $\left(F=8.08, p<0.01, \mathrm{r}^{2}=0.28\right)$. This suggest that the Spanish index could serve as a crude indicator of purse seine catch rates on the same cohort during the follow- 


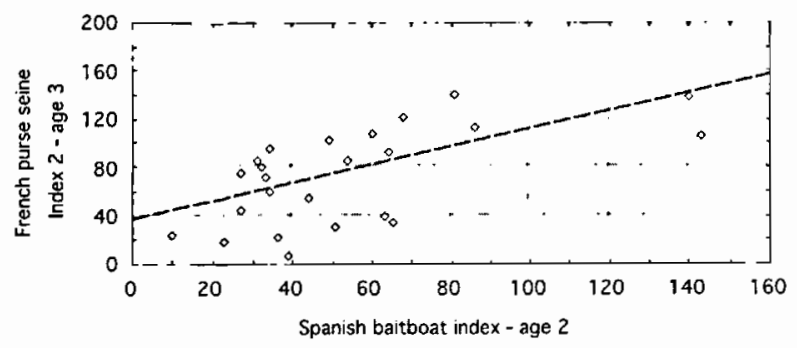

Figure 7. - Arithmetic mean CPUE of French purse seine catches of age 3 hluetin, against that of the Spanish baitboat for catches of age 2 bluefin in the previous year. Linear regression line shown for reference purposes only.

ing year (Fig. 7). This observation supports the hypothesis that some age 2 bluefin move from the Bay of Biscay to the Gulf of Lions, as revealed by the juvenile tagging programs (Cort and Liorzou, 1991).

All indices showed considerable variation, and a slight increase over 1970-95 that corresponds to a reduction in the proportion of trips with no age 2 catches (Index 5). However, indices 2-5 differ substantially in terms of precision. Some of the lower bounds for indices 2-3 are negative (but bounded by zero in Fig. 6), and there is a tendency for higher indices to have greater coefficients of variation. This observation has important implications when inverse-variance weighing (Hilborn and Walters, 1992 p. 232) is used to calibrate SPA models, since high CPUE indices give more weight to low stock sizes. By contrast, the bounds associated with indices $4-5$ are not distinctly wider for larger values, and none of the lower bounds are negative.

\section{DISCUSSION}

The results presented indicate that the present algorithm can be used to predict the length frequencies of the bluefin caught by French purse seine vessels based on the analysis of sale records. The predictive ability of the new algorithm is superior to that of the previous one used by Liorzou and Bigot (1992). Unfortunately, detailed measurements were not made on landings of large bluefin, so it cannot be demonstrated that the present algorithm can accurately predict the length frequencies of all bluefin caught by the French purse seine fleet in the Mediterranean. Ideally, catch sampling should be conducted at several locations throughout the year to determine if the predictions are sufficiently accurate for ICCAT assessments. If so, then one might rely on this algorithm to provide the length frequency data required by ICCAT each year, since it may be more cost-effective to collect, process and analyze sale records than to conduct labor intensive, catch monitoring operations at night when the catches are unloaded.

Despite the encouraging results, the predicted and observed frequencies were not identical, and the possi- bility exists that large discrepancies will be detected when landings of larger bluefin are sampled. This leads us to determine how the present algorithm could be improved. In the present study, growth patterns are predicted using the von Bertalanffy parameter estimates of Cort (1991). The author estimated these using length-at-age data based on visual counts of spine circuli taken from bluefin in a narrow size range. The length-at-age of bluefin outside this range were either back-calculated or estimated by reference to those of small bluefin. These data are not entirely independent, and owing to "Lee's phenomena" (Ricker, 1975, p. 215), the back-calculated length-at-age tends to be smaller than actual length at the corresponding age and time. It would thus seem advisable to estimate all growth parameters simultaneously, using independent length-at-age measurements, or by analyzing a properly stratified set of length frequencies with the MULTIFAN application (Fournier et al., 1990).

If ages are estimated, sophisticated techniques should be used, since the number of spine circuli does not accurately represent the age of large bluefin due to the resorption of the spine core and the compression of the outer circuli. As a result, estimates of ages beyond 15 years have been qualified as being controversial (Mather et al., 1995, p. 5). Knowledge of the actual variation in size-at-age could also improve the present algorithm. As noted earlier, the coefficients of the regression of the standard deviation of length-at-age against the mean were estimated from the ages 9-15 figures reported by Cort (1991, p. 218). If the ages 1-3 figures reported by Cort (1991, p. 223) are included in the data set used for this regression, slightly different coefficient estimates are obtained, and smaller standard deviations are predicted for the younger ages. The two sets of figures were not pooled because they were from different sources, but this observation highlithts need for accurate information on this subject.

Knowledge of the historical mortality profiles acting on each cohort could also improve the accuracy of the predictions. It is beyond the scope of this study to describe the effects of a multitude combinations of natural and fishing mortalities. However, sensitivity analyses indicate that the algorithm is not sensitive to increases in natural mortality if constant across all age groups (results not shown). If higher rates act on the young bluefin, or on mature females due to the stress caused by reproduction, then their predicted contributions decreases. The shape of the length frequency histogram changes depending on this differential mortality, but not the CPUE trends based on age 2 catches.

Mis-representing past fishing mortality has similar impacts on both types of predictions, but more on the predicted length frequencies. Using the most up-todate SPA results in the algorithm limits the usefulness of the indices, since these cannot be used in turn to calibrate the SPA model (a self-tuning process). In the absence of an alternate data source, the present algo- 
rithm must rely on general trends in SPA results to account for past exploitation, or ignore its impacts altogether. The first option was chosen in the hope of making more realistic predictions, but the drawback is a partial loss of independence between the predicted indices of abundance and the SPA results. The previous algorithm used by Liorzou and Bigot (1992) does not suffer from this limitation, and in this limited sense, is better suited for calibration purposes. However, one cannot justify the use of the older algorithm based only on this last criteria, especially if efforts are made to minimize the use of SPA results. To comply with this last objective as much as possible, indices of year class strength from SPA results were not used in the present algorithm for predictive purposes. Ideally, estimates of year class strength and mortality rates should be obtained from alternative sources whenever possible, such as from large-scale tagging programs, and estimates of age-specific catches in large tuna traps (madrague) in Morocco, Spain and Italy.

With regards to the second objective of this study, the results do not clearly demonstrate that any particular CPUE index is a better indicator of abundance trends. Meyers and Pepin (1990) noted that lognormal estimators (index 3 ) are less efficient than sample means when non-zero values are not lognormally distributed, the coefficients of variation (CV) of non-zero values are 2.0, and the proportion of zero values is high. Pennington (1990) obtained estimates more efficient than the sample mean under such conditions, with sample sizes of 40 that included high proportions of zero values $(44 \%)$. However some of the present data sets were smaller, had atypical distributions of non-zero values, and a higher CV (>2.2). Furthermore, many of the zeros resulted from the age dissagregation process, and are not akin to actual counts. Given such facts, one could hypothesize that the index 3 scores are more biased than their index 2 counterparts.

By contrast, index 4 does not have to meet the above criteria. The lower bounds of the scores are more reasonable $(>0)$ than those of index 2 , and the scores are well correlated with index 5 and the spanish baitboat index for age 2 catches. Thus, one could hypothesize that index 4 reflects more accurately the trends in abundance. However this is largely a matter of conjecture given the uncertain relation between CPUE and abundance (sce Peterman and Steer, 1981; Richards and Schnute, 1986). If one relies on arguments such as the "triangle of agreement" (Squire, 1993) to determine which index to rely on, then index 2 is preferred in spite of its theoretical limitations since it agrees most with the spanish baitboat index. Still, such results highlight the need to conduct complementary surveys to determine which index is the best indicator of juvenile abundance.

The slight general increase in CPUE shown by indices 1-4 is considered to be informative. This could result from increased fishing efficiencies in the purse seine fleet. Unfortunately, the lack of data fishing gear and harvest strategies does not allow us to standardize CPUE scores by means of GLMs (McCullagh and Nelder, 1989) to account for plausible increases in catchability that often accompany technological developments. However, the Spanish baitboat fishery has not adopted new practices in the last decades (J.L. Cort, pers. comm.), and it seems unlikely that small, incremental improvements in fishing efficiencies are taking place in both fisheries simultaneously. The patterns observed lend support to the hypothesis that juvenile abundance varies considerably over time, and has remained relatively stable in recent years despite increasing exploitation.

Squire (1993) reported large variation in abundance indices for bluefin tuna (Thunnus thynnus) in the western Pacific during 1962-90. The author noted that the period of peak bluefin abundance corresponded to that of the northern anchovy (Engraulis mordax). Polovina (1996) hypothesized that climate-induced changes in the abundance of the Japanese sardine (Sardinops melanosticta) had a major influence on the trans-Pacific migration of bluefin tuna. Presumably, the distribution and abundance of juvenile bluefin in the Mediterranean is also influenced by that of its principal preys, such as anchovy (Engraulis encrasicolus) and sardine (Sardina pilchardus).

Hydro-acoustic surveys of small pelagic species are routinely conducted by IFREMER staff in coastal waters of southern France for ecological studies. However, these are not extensive enough to determine if the stock sizes of small pelagic species are a major determinant of the relative abundance of juvenile bluefin in the western Mediterranean. Even if they were, the apparent predator-prey relations would be ill-defined if purse seine CPUE were used as indices of bluefin abundance. When the bluefin school density is high, scine vessels may not be able to exploit every school because of the net handling times. Under such conditions, the fishing gear is "saturated", so purse seine CPUE is not a good indicator of abundance beyond a certain threshold value. For this reason, a good measure of effort should break down fishing time into search time, travelling and net handling periods (Gulland, 1983). Requesting this level of detail in logbooks may not be practical, so indices of abundances should rely on alternative type of data.

It is also a well known fact that the densities of pelagic species can remain constant in some areas when stock size is decreasing (Hillborn and Walters, 1992). If fishing is concentrated on the best areas, a reduction in total abundance might not be detected from CPUE changes. The Spanish and French fisheries each take place on traditional grounds, and purse seine vessels that operate outside these grounds are excluded from the analysis to reduce the need for standardization. Thus, even if CPUE trends reflect changes in local abundance, they may not serve as an accurate measure of total abundance, which is needed to calibrate SPA models. Idealy, future monitoring programs 
should be designed to provide data on the spatial and temporal distributions of purse seine effort, vessel attributes, empty sets, and surface schools to provide more representative indices of directed effort and catch rates.

Aerial surveys are routinely used to assess the absolute and relative abundance of pelagic species in other regions (Lo et al., 1992; Squire, 1993; Lutcavage and Kraus, 1995; Lutcavage et al., 1996). It might prove worthwhile to use such methods to monitor fishing activity and bluefin abundance in the western Mediterranean. The results of the present study could help design an aerial survey that would complement the present data collection program, and help assess the cost-effectiveness of various options proposed for fishery monitoring purposes.

\section{REFERENCES}

Anonymous 1995a. Characterization of large pelagic stocks (Thunnus thynnus, Thunnus alalunga, Sarda sarda, Xiphias gladius) in the Mediterranean. Commission of the European Communities. Directorate General for Fisheries (DG XIV). Contract n XIV MED/91/012. Final Report, $118 \mathrm{p}$.

Anonymous $1995 b$. International Commission for the Conservation of Atlantic Tunas. Report for biennial period, 1994-95. Part I - Vol. 2, Madrid, Spain, 283 p.

Anonymous 1996. Thon rouge en Méditerranée : une filière en pleine (r)évolution. Rapport CEPRALMAR, $30 \mathrm{p}$.

Bannerot S. P., C. B. Austin 1983. Using frequency distributions of catch per unit effort to measure fish-stock abundance. Trans. Am. Fish. Soc: 112, 608-617.

Bayliff W. H. 1995. Indices of abundance of northern bluelin tuna, Thunnus thynnus, in the eastern Pacific ocean. In: Status of interactions of Pacific tuna fisheries in 1995. Shomura R. S., J. Majkowski, R. F. Harman eds. FAO Fish. Tech. Pap. 365, 460-475.

Cort J. L. 1991. Age and growth of the bluefin tuna, Thunnus thynnus (L.) of the Northeast Atlantic. ICCAT/SCRS/90/ $66,213-230$.

Cort J. L. 1994. Datos de la Pesquería de atún rojo del mar Cantábrico. ICCAT/SCRS/94/91, 289-292.

Cort J. L., B. Liorzou 1991. Tagging interpretation - eastern Atlantic and Mediterranean sea. Inter-Am. Trop. Tuna Comm. Spec. Rep. 7, 110-128.

Deriso R. B., W. H. Bayliff eds. 1991. World meeting on stock assessment of bluefin tunas: Strengths and Weaknesses. Inter-Am. Trop. Tuna Comm. Spec. Rep. 7, 357 p.

Farrugio H. 1977. Données préliminaires sur la pêche au thon rouge au filet tournant en Méditerranée française. ICCAT Coll. Vol. Sci. Pap. 6, 245-252.

Farrugio H. 1981. Exploitation et dynamique des populations de thon rouge Thunnus thynnus (L., 1758). Thèse dr. Univ. Sci. Tech. Languedoc, Montpellier, $325 \mathrm{p}$.

Fournier D. A., J. R. Sibert, J. Majkowski, J. Hampton 1990. MULTIFAN a likelihood-based method for estimating growth parameters and age composition from multiple length frequency data sets illustrated using data for southern bluefin tuna (Thunnus maccoyii). Can. J. Fish. Aquat. Sci. 47, 301-317.
Gulland J. A. 1983. Fish stock assessment. John Wiley \& Sons. N. Y. New York, $223 \mathrm{p}$.

Hampton J. 1991. Estimation of southern bluefin Thunnus maccoyii growth patterns from tagging data, using von Bertalanffy models incorporating individual variation. Fish. Bull. 89, 577-590.

Hilborn R., C. J. Walters 1992. Quantitative Fisheries Stock Assessment. Chapman and Hall, New York, NY, USA, $570 \mathrm{p}$.

IMSL 1989. FORTRAN subroutines for mathematical applications. Math Library Version 1.1 IMSL Inc. Sugarland, Texas, USA, $1150 \mathrm{p}$.

Labelle M., J. Hampton, K. Bailey, T. Murray, D. A. Fournier, J. R. Sibert 1993. Determination of age and growth of South Pacific albacore (Thunnus alalunga) using three methodologies. Fish. Bull. 91, 649-663.

Liorzou B., J. L. Bigot 1992. Actualisation des données sur le thon rouge exploité au large des côtes françaises de Méditerranée. ICCAT/SCRS/92/139, 7 p.

Lo N. C., L. D. Jacobson, J. L. Squire 1992. Indices of relative abundance from fish spotter data based on Delta-Lognormal models. Can. J. Fish. Aquat. Sci. 49, 2515-2526.

Lutcavage M., S. Kraus 1995. The feasibility of direct photographic assessment of giant bluclin tuna, Thunnus thynnus, in New England waters. Fish. Bull. 93, 495-503.

Lutcavage M., S. Kraus, W. Hoggard 1996. Aerial survey of giant bluefin tuna, Thunnus thynnus, in the Great Bahama bank, Strait of Florida, 1995. Fish. Bull. 95, 300-310.

Mather F. J., H. A. Schuck 1960. Growth of bluefin tuna of the western North Atlantic. Fish. Bull. 179, 39-52.

Mather F. J., J. M. Mason, A. C. Jones 1995. Historical document: life history and fisheries of Atlantic bluefin tuna. NOAA Technical Memorandum, NMFS-SEFSC-370, $165 \mathrm{p}$.

McCullagh P., J. A. Nelder 1989. Generalized Linear Models. Second edition. Monograph on Statistics and Applied Probability 37. Chapman \& Hall, New York, USA, 511 p.

Myers R. A., P. Pepin 1990. The robustness of lognormalbased estimators of abundance. Biometrics 46, 1185-1192.

Pauly D., G. Gaschütz 1979. A simple method for fitting oscillating length growth data, with a program for pocket calculators. ICES C.M. G:24, 26 p.

Pennington M. 1983. Efficient estimators of abundance, for fish and plankton surveys. Biometrics 39, 281-286.

Pennington M. 1990. On testing the robustness of the lognormal-based estimators. Biometrics 47, 1623-1624.

Peterman R. M., G. Steer 1981. Relation between sport-fishing catchability coefficients and salmon abundance. Trans. Am. Fish. Soc. 110, 585-593.

Polovina J. J. 1996. Decadal variation in the trans-Pacific migration of northern bluefin tuna (Thunnus thynnus) coherent with climate-induced change in prey abundance. Fish. Oceanogr. 5, 114-119.

Press W. H., S. A. Teukolsky, W. T. Vetterling, B. P. Flannery 1992. Numerical recipes. The art of scientific computing (2nd ed.). Cambridge University Press. Cambridge, U.K., $963 \mathrm{p}$.

Ricker W. E. 1975. Computation and interpretation of Biological statistics of fish populations. Fish. Res. Board Can. Bull. 191, 382 p.

Richards J. L., J. T. Schnute 1986. An experimental and statistical approach to the question: is CPUE an index of abundance. Can. J. Fish. Aquat. Sci. 43, 1214-1227. 
Richards J. L., J. T. Schnute 1992. Statistical models for estimating CPUE from catch and effort data. Can. J. Fish. Aquat. Sci. 69, 1315-1327.

Smith J. S. 1988 . Evaluating the efficiency of the $\Delta$-distribution mean estimator. Biometrics 6\&, 485-493.

Squire J. L. 1993. Relative abundance of pelagic resources utilized by the California purse-seine fishery: Results of an airborne monitoring program, 1962-90. Fish. Bull. 91, 348-161.

Stefánsson G. 1996. Analysis of groundfish survey abundance data: combining the GLM and delta approaches. ICES J. Mar. SCi. 53, 577-588.

Zar J. H. 1984. Biostatistical Analysis. Second Edition, Prentice-Hall. New Jersey, 718 p. 